\title{
Implementasi Penjaminan Mutu pada Lembaga PAUD di Solo Raya
}

\author{
Feri Faila Sufa ${ }^{\varpi_{1}}$, M Hery Yuli Setiawan ${ }^{2}$ \\ Pendidikan Guru Pendidikan Anak Usia Dini, Universitas Slamet Riyadi \\ DOI: $10.31004 /$ obsesi.v4i2.408
}

\begin{abstract}
Abstrak
Pendidikan anak usia dini mempunyai peran strategis terhadap perkembangan manusia. Oleh karena itu perlu pendidikan yang bermutu. Tujuan penelitian ini adalah untuk mengetahui bagaimana upaya yang dilakukan pemerintah untuk meningkatkan mutu PAUD. Pendekatan kualitatif dilakukan menggunakan metode wawancara, observasi dan dokumentasi di area Solo Raya untuk melihat bagaimana lembaga PAUD mengupayakan mutunya. Hasil penelitian menunjukkan bahwa untuk mencapai mutu lembaga PAUD, dilakukan melalui penjaminan mutu internal dan eksternal. Mutu internal PAUD dilakukan melalui pemetaan mutu oleh dinas pendidikan dan melalui peningkatan mutu eksternal melalui badan akreditasi Nasional Pendidikan Pendidikan anak usia dini dan Pendidikan non formal (BAN PAUD PNF).
\end{abstract}

Kata Kunci: mutu paud; standar paud; ban paud pnf.

\begin{abstract}
Quality Educational institutions for early childhood are needed as a basis for more optimal human development. After increasing ECE access successfully, the quality of Early sChildren Education (ECE) becomes the government's focus. This is because there are only a few ECE institutions that have not standardized ECE institutions as explained in Minister of Education regulation number 137 of 2014 concerning national ECE standards. Therefore, the government encourages that by 2020 all ECE institutions can be accredited. The purpose of this study is to find out how the efforts made by the government to improve the quality of ECE. A qualitative approach was carried out using the method of interview, observation and documentation in the Solo Raya area to see how ECE institutions sought their quality. The results of the study explained that in improving the quality of ECE institutions through internal and external quality assurance. ECE internal quality is carried out through quality mapping by the education office and through external quality improvement through the National Accreditation Board for Early Childhood Education and Non-formal Education
\end{abstract}

Keywords: quality of ece ; standards of ece; national accreditation board for ece and non-formal education

Copyright (c) 2020 Feri Faila Sufa, M Hery Yuli Setiawan

$\square$ Corresponding author:

Email Address : ferifailasufa@unisri.ac.id (Surakarta, Indonesia)

Received 23 December 2019, Accepted 30 December 2019, Published 10 January 2020 


\section{PENDAHULUAN}

Pada usia awal kehidupan manusia, terjadi perkembangan dan pertumbuhan yang sangat cepat baik secara fisiologis, perkembangan social maupun kognitif anak. Karena itu pada awal tahun kehidupan manusia atau usia dini perlu mendapatkan perhatian agar memberikan pijakan yang kuat pada perkembangan selanjutnya. Banyak pendapat yang menjelaskan pentingnya pendidikan anak usia dini. (Siraj-Blatchford, 2009) dan mendidik gurunya dalam memberikan pengalaman pada pendidikan awal sebagai pengenalan pada lingkungan belajar yang direncanakan dan diorganisasikan dengan cermat dapat membanguan pemahaman mereka pada dunia mereka. (House et al., 2007), Peraturan menteri nomer 137 tahun 2014 menjelaskan pendidikan awal pada usia dini dimulai dari sejal lahir hingga 6 tahun. Pada usia itu perlu diberikan stimulasi pada aspek jasmani, bahasa, kognisi, sosial emosi maupun bahasa. (Pendidikan, Kebudayaan, \& Indonesia, 2014). Montessori menyebut masa ini sebagai masa emas, masa peka atau masa sensitif.((Montessori \& Burstyn, 1982), (TUBAKI \& MATSUISHI, 1972)

Usia dini yang berperan strategis pada perkembangan kehidupan manusia membutuhkan kualitas yang bagus dalam pendidikannya. (Ereky-stevens, n.d., 2001) dalam sebuah reviewnya terhadapa dampak pendidikan untuk uisa awal, menjelaskan bahwa PAUD yang berkualitas tinggi dapat meningkatkan kognitif dan non kognitif anak-anak yang kurang beruntung. Pada dekade terakhir ini pemerintah sangat memperhatikan PAUD, namun begitu, masih banyak permasalahan berkaitan dengan pengelolaan lembaga PAUD. Standar pendidik yang tidak relevan dengan kompetensinya, fasilitas yang kurang memadai baik saran maupun pra sarana. Maupun buruknya pengelolaan kelembagaan. Sebagai contoh, masih ditemukan kepala sekolah yang merangkap sebagai guru, bangunan rumah yang digunakan untuk proses pembellajaran, guru yang tidak sesuai bidangnya ataupun masih lulusan SMA. Dan dukungan orang tua dan masyarakat yang kurang untuk mendukung kemajuan pendidikan anak.

Untuk mencapai generasi Emas, tentu saja bukan hanya akses PAUD yang perlu menjadi concern pemerintah, namun mutu lembaga PAUD juga perlu menjadi perhatian. Semangat mendirikan lembaga PAUD yang sangat pesat sekali, perlu diimbangi dengan semangat meningkatkan mutu atau kualitas lembaga PAUD yang di standarkan pemerintah mengacu pada peraturan pemerintah nomer nomor 137 tahun 2014 tentang standar nasional pendidikan PAUD(Pendidikan et al., 2014).

Kenyataannya masih banyak lembaga PAUD yang belum melakukan kegiatan penjaminnan mutu, baik secara internal melalui pemetaan mutu, maupun pelaksanaan mutu internal melalui badan akreditasi. Target BANPAUD sendiri ditahun 2020 semua lembaga PAUD sudah terakreditasi. Oleh karena itu perlunya lembaga PAUD untuk meningkatkan kualitas melalui penjaminan mutu baik secara internal maupun eksternal.

Penelitian (Farquhar, 1990) tentang apa definisi yang jelas tentang kualitas pendidikan dan perawatan anak usia dini. Hal ini karena tidak ada ukuran yang tunggal yang dapat dilakukan dari berbgai pendekatan untuk menilai kualitas pendidikan anak usia dini. Maka hal yang penting dari sudut pandang tenaga kependidikan. Orang tua, budaya dan temuan penelitian tentang anak yang dapat menentukan kualitas pendidikan. (Bernard van Leer Foundation, 2008) dalam penelitian Rosalia di kota anak melakukan assessment kualitas dalam prakteknya oleh center for culture and Development ( CPCD ) sebuah pusat kebudayaan dan pengembangan dengan indicator; (1) Keseuaian anatara apa yang menjadi visi dengan capaiannya. (2) Koheren, yang menunjukkan adanya hubungan teori dan praktek, yang menunjukkan keduanya sangat penting. (3) Kerjasama, semangat tim, dan solidaritas (4)Kreatifitas, berupa inovasi, hiburan (5) Dinamis, kemampuan berubah sesuai kebutuhan(6) efisiensi, yang termasuk learning to know, learning to di, learning to be, learning to live together (7) estetik yang mengacu pada keindahan. (8) Kebahagiaan (9) keselarasan, rasa saling menghormati (10) Kesempatan dengan menciptakan peluang (11) 
memimpin sebagai bagian dalam membuat keputusan penting dalam menghadapi tantangan. (12) Transformasi sebagai agen perubahan.

Mutu pendidikan sebenarnya menjadi fokus dalam tahapan pembangunan yang di jelaskan dalam perencanaan pembangunan jangka panjang Nasional tahun 2005-2025. Pada tahpa ke tiga (pada tahun 2015-2019) lebih menekankan pada keunggulan yang kompetitif. Pembangunan ekonomi yang berbasis sumber daya alam, sumber daya manusia yang berkaulitas serta kemampuan IPTEK, maka salah satu capaiannya adalah tercipta keluasan dan kemerataan akses PAUD bermutu, berkesetaraan jender, dan berwawasan pendidikan untuk pembangunan berkelanjutan (ESD) dan kewarganeraan global di semua provinsi, kabupaten, dan kota. Oleh karena itu lembaga PAUD yang bermutu menjadi fokus pemerintah dalam rangka menyiapkan sumber daya manusia sejak dini.

Salah satu cara paling mudah untuk mengetahui mutu satuan pendidikan adalah melihat status akreditasinya. Cara itu berlaku untuk semua jenjang pendidikan mulai pendidikan anak usia dini (PAUD), pendidikan dasar dan menegah, hingga perguruan tinggi (PT). Mutu pendidikan nonformal (PNF), lembaga kursus, dan pelatihan juga dapat dinilai dari status akreditasinya. Semakin baik status akreditasi suatu pendidikan berarti proses penjaminan mutunya semakin terjaga.

Dalam sebuah Studi penjaminan mutu PAUD selama Februari-Mei 2015 yang disampaikan oleh Gutama dan Fitria Herarti dalam Lokakarya hasil Studi ACDP022 di Jakarta menyimpulkan bahwa dukungan dan manfaat PAUD sudah diketahui secara luas, dan telah dilakukan banyak akses layanan PAUD namun belum dibarengi dengan meingkatnya mutu PAUD. Maka artikel ini akan membahas bagaimana implemetasi penjaminan mutu di lembaga PAUD. Mutu pada PAUD di Indonesia sudah distandarisasikan sesuai peraturan menteri pendidikan nomer 137 tanhun 2014 tentang standar PAUD Nasional. Namun mutu Mutu menurut para ahli antara lain Crosby menjelaskan mutu ialah conformance to requirement, yaitu sesuai dengan yang disyaratkan atau distandarkan. Deming menyatakan mutu ialah kesesuaian dengan kebutuhan pasar atau konsumen, Feigenbaum menyebutkan mutu adalah kepuasan pelanggan sepenuhnya dan Davis (1994) menyatakan mutu ialah suatu kondisi yang berhubungan dengan produk, tenaga kerja, proses dan tugas serta lingkungan yang memenuhi atau melebihi harapan pelanggan. Namun (Gambaro, Stewart, \& Waldfogel, 2015) menjelaskan kualitas bukan berdasarkan dokumen melainkan juga melihat indikator kualitas secara keseluruhan dalam kinerja pendidikan dan pengasuhannya.

\section{METODOLOGI}

Penelitian ini menggunakan pendekatan kualitatif. Lokasi penelitian berlokasi di area Solo Raya meliputi lembaga PAUD yang mewakili daerah Sukoharjo sejumlah 3 lembaga, Karanganyar 2 lembaga, sragen dengan 5 lembaga dan Surakarta, berjumlah 2 lembaga. Peneliti menggali data terkait pelaksanaan manajemen mutu dan program terkait penjaminan mutu melalui wawancara kepada kepala sekolah dan guru, melakukan pengamatan dilembaga, dan telaah dokumentasi. Hasil atau temuan dari observasi dan wawancara akan didiskusikan di tahap berikutnya, melalui grup discussion. Tahap berikutnya adalah melakukan Forum Grup Discussion (FGD). Hal yang didiskusikan pada FGD berkaitan hasil observasi, maupun untuk menggali data yang belum ditemukan demikian juga dalam hal melakukan pengecekan atau konfirmasi terhadap persepsi yang ditafsirkan oleh peneliti. Hal yang didiskusikan pada FGD berkaitan dengan penjaminan mutu internal maupun eksternal, dan pelaksanaan standar 1 sampai 8. Analisis data yang digunakan menggunakan model interaksi analisis data kualitatif. 


\section{HASIL DAN PEMBAHASAN}

Mutu PAUD menjadi prioritas pemerintah setelah peningkatan akses layanan PAUD sudah berhasil di capai, dengan minimal setiap desa ada satu lembaga PAUD. Untuk mencapai hal tersebut perlu dorongan pemerintah dalam mendorong kuantitas maupun kualitas. (Ishimine \& Tayler, 2014) menjelaskan dampak kualitas sebagai dampak dari konten bahasa, numeracy, perkembangan social dan emosional yang dikembangkan di Amerika Serikat.

Untuk mencapai mutu lembaga PAUD yang terstandarisasi, maka pemerintah mengeluarkan peraturan menteri nomer 137 tahun 2014 tentang standar nasional PAUD yang meliputi 8 standar. (1) Standar Tingkat Pencapaian Perkembangan anak (STPPA) sebagai standar kompetensi lulusan (SKL) dari lembaga PAUD. (2) Standar isi Standar tersebut merupakan kriteria minimalmerupakan standar pengembangan dalam bentuk tema dan sub tema.(3) standar proses meliputi perencanaan, pelaksanaan, evaluais dan pengawasan. (4) satndar penilaian merupakan proses dan hasil pembelajarandalam STPPA. (5) standar pendidik dan tenaga kependidikan berhubungan dengan tenaga profesional yang bertugas merencanakan, melaksanakan dan menilai hasil pembelajaran. (6) standar sarana prasarana merupakan perlengkapan dalam penyelenggaraan pengelolaan pendidikan berkaitan dengan pelaksanaan pendidikan. (7) Standar pengelolaan sebagai pelaksanaan dari standar isi, proses, pendidik dan tenaga kependidikan, sarana dan prasarana dan pembiayaan. (8) Standar pembiayaan meliputi komponen pembiayaan pendidikan yang terdiri biaya operasional pendidikan dan biaya personal anak.(Pendidikan et al., 2014)

Semua Standar pelaksanaan pendidikan termasuk di lembaga PAUD mengacu pada Badan Standar Nasional Pendidikan (BSNP) yang menjadi dasar dalam melakukan perencanaan, pelaksanaan, dan pengawasan pendidikan untuk mewujudkan pendidikan nasional yang berkualitas. Namun ada sedikit perbedaan standar pendidikan pada standar nasional pendidikan dan standar nasional PAUD, meskipun hanya berupa urutan standar, yang akan di sandingkan pada tabel 1 .

Tabel 1. Standar Minimal pelayanan Pendidikan

\begin{tabular}{cll}
\hline Standar & $\begin{array}{l}\text { Permendikbud } \\
137 / 2014\end{array}$ & BNSP \\
\hline 1 & STPPA & SKL \\
2 & Standar Isi & Standar Isi \\
3 & Standar Proses & Standar Proses \\
4 & Standar Penilaian & $\begin{array}{l}\text { Standar Pendidikan dan Tenaga } \\
\text { Pendidikan }\end{array}$ \\
5 & Standar Pendidik dan tenaga & Standar Sarana Prasarana \\
& pendidikan & \\
6 & Standar Sarana dan prasarana & Standar Pengelolaan \\
7 & Standar pengelolaan & Standar Pembiayaan Pendidikan \\
8 & Standar pembiayaan & Standar Penilaian Pendidikan \\
\hline
\end{tabular}

Dalam implementasinya, pelaksanaan mutu di lembaga PAUD dilakukan secara internal maupun eksternal. Mutu internal dilakukan di dalam lembaga, melalui kegiatan pemetaan mutu PAUD sesuai standar nasiomal pendidikan merujuk peraturan menteri nomer 137 tahun 2014 tentang standar nasional PAUD dan Peraturan menteri nomor 146 tentang kurikulum 2013 PAUD. Sedangkan penjamin eksternal dilakukan oleh Badan Akreditasi Nasional Pendidikan Anak Usia Dini dan Pendidikan Non Formal (BAN PAUD dan PNF). Implementasi kegiatan mutu di lembaga PAUD di jelaskan pada gambar 2. 


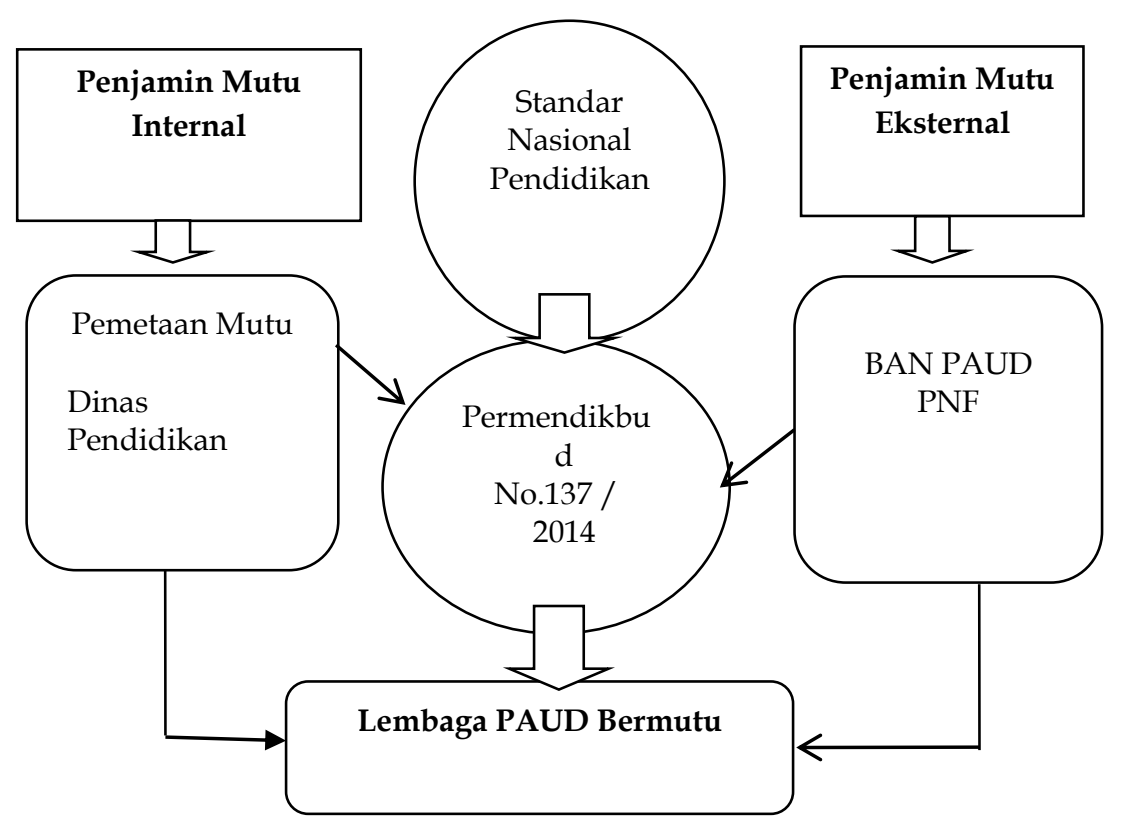

Gambar 2. Kegiatan Mutu

Dalam Rencana Strategis Sekretariat Dierktorat Jenderal Pendidikan Anak Usia Dini dan Pendidikan Masyarakat Tahun 2015-2019 bahwa salah satu Visi Kementerian Pendidikan dan Kebudayaan adalah membentuk insan dan ekosistem pendidikan dan kebudayan yang berkarakter berlandaskan Gotong Royong. Untuk mewujudkan visi tersebut ditetapkan lima misi. Salah satunya merupakan upaya mencapai mutu pembelajaran. Misi tersebut untuk mewujudkan : (1) Pelaku pendidikan dan Kebudayaan yang Kuat. (2) Akses Meluas, Merata, dan Berkeadilan. (3) Pembelajaran Bermutu. (4) Pelestarian Kebudayaan dan Pengembangan Bahasa. (5) Penguatan Tata Kelola serta Peningkatan Efektivitas Birokrasi dan Pelibatan Publik. Dengan implementasi melalui : (i) reformasi program; (ii) strategi pendanaan pendidikan; (iii) sistem tata kelola dan pengawasan internal, (iv) sistem monitoring dan evaluasi yang menjamin terlaksananya fungsi serta tercapainya tujuan PAUD-Dikmas, dan (v) Pemanfaatan Teknologi dan Informasi. Langkah tersebut dilakukan sebagai upaya peningkatan mutu pendidikan Aank usia dini. Mutu perlu dijelaskan (Goldberg \& Cole, 2002) mutu dilakukan untuk membangun kinerja yang unggul dalam performanya.

Berkaitan dengan pentingnya PAUD bermutu dengan perkembangan anak, menurut (Rao, Richards, Sun, Weber, \& Sincovich, 2019) Dalam penelitiannya menjelaskan bahwa anak yang mengikuti program early children education atau di Indonesia dengan istilah PAUD menemukan bahwa durasi lamanya waktu layanan anak di PAUD memberikan kontribusi terhadap perkembangan kognitif, bahasa, dan sosial-emosional anak. Di Indonesia layanan PAUD rata-rata 3 jam perhari, berbeda dengan china sekitar 5 jam perhari sesaui permendiknas No. 137 tahun 2013. Jadi Peningkatan mutu PAUD dilakukan agar perkembangan anak berkembang secara optimal.

Di Indonesia, Instrumen mutu PAUD BAN PAUD dan PNF merujuk pada peraturan pemerintah tentang standar nasional pendidikan dalam indikator penilaiannya. Namun berkaitan dengan mutu PAUD banyak intrument yang dapat digunakan, seperti The Classroom Assessment Scoring System (CLASS), ECERS, dalam mendapatkan standar mutu PAUD, yang dapat dilihat pada tabel 2. Instrumen yang digunakan dalam mutu PAUD selalu di update dan di evaluasi. Jika sebelum tahun 2019 mutu PAUD berbasis dokumen, maka pada tahun 2019 berbasis performance. (Schulz, 2015) menjelaskan prktek dokumentasi di paud dilakukan sebagai subyek penelitian dalam proses pembelajaran anak. 
Tabel 2. Pengukuran Mutu PAUD

\begin{tabular}{|c|c|c|}
\hline Nama & Fokus & sumber \\
\hline Child Caregiver Interaction Scale & Emosional, kognitif, fisik dan sosial & Arnett (1989) \\
\hline $\begin{array}{l}\text { Early Childhood Environmental } \\
\text { Rating Scale- Revised Edition } \\
\text { (ECERS-R) }\end{array}$ & $\begin{array}{l}\text { Sarana prasarana (space anak bergerak, } \\
\text { peralatan dan perawatan yang digunakan, } \\
\text { bahasa, aktivitas, interaksi, orang tua dan } \\
\text { staff }\end{array}$ & $\begin{array}{l}\text { Harms, Clifford \& } \\
\text { Cryer (1998) }\end{array}$ \\
\hline $\begin{array}{l}\text { Early Childhood Environment } \\
\text { Rating Scale - Extension (ECERS- } \\
\text { E) }\end{array}$ & Literasi, Matematika, Sains & $\begin{array}{lr}\text { Sylva, } & \text { Siraj- } \\
\text { Blatchford } & \& \\
\text { Taggart (2003) } & \\
\end{array}$ \\
\hline $\begin{array}{l}\text { Infant/Toddler } \quad \text { Environment } \\
\text { Rating Scale (ITERS-R) }\end{array}$ & $\begin{array}{l}\text { Sarana prasarana mendengar, dan } \\
\text { berbahasa, aktivitas, interaksi, orang tua dan } \\
\text { staff }\end{array}$ & $\begin{array}{l}\text { Harms, Cryer \& } \\
\text { Clifford (2003) }\end{array}$ \\
\hline $\begin{array}{l}\text { Observational Record of the } \\
\text { Caregiving Environment (ORCE) }\end{array}$ & $\begin{array}{l}\text { Dampak positif dan negatif pada bahasa dari } \\
\text { Interaksi simulasi pada anak dengan lainnya }\end{array}$ & Vandell (1996) \\
\hline $\begin{array}{l}\text { Child/Home Early Language \& } \\
\text { Learning Literacy Observation } \\
\text { Tool (CHELLO) }\end{array}$ & $\begin{array}{l}\text { Obsevasi pada aspek Literasi, Lingkungan } \\
\text { Grup/keluarga }\end{array}$ & $\begin{array}{l}\text { Neuman, Koh \& } \\
\text { Dwyer (2008) }\end{array}$ \\
\hline $\begin{array}{l}\text { Classroom Assessment Scoring } \\
\text { System (CLASS) }\end{array}$ & $\begin{array}{l}\text { Dukungan Desain pembelajaran di ruang } \\
\text { kelas dan sosial emosi }\end{array}$ & Pianta et al. (2008) \\
\hline $\begin{array}{l}\text { Early Language \& Literacy } \\
\text { Classroom Observation Pre-K Tool } \\
\text { (ELLCO Pre-K) }\end{array}$ & $\begin{array}{l}\text { Struktur kulrikulum di kelas, bahasa dan } \\
\text { lingkungan pembelajaran }\end{array}$ & $\begin{array}{l}\text { Smith, Brady \& } \\
\text { Anastasopoulos } \\
\text { (2008 }\end{array}$ \\
\hline
\end{tabular}

(sumber : Halle, Vick Whittaker \& Anderson 2010)

Dalam mengukur kualitas PAUD, Halle, Vick Whittaker \& Anderson (2010) menjelaskan ada Setidaknya ada lima puluh skala kualitas yang tersedia. Salah satu yang paling berpengaruh untuk menganalisis kualitas proses adalah melalui kerangkang berpikir pembelajaran yang oleh Hamre (2014) di bagimenjadi 3 bagian penting, Yaitu (1) dukungan emosional. (2) Pengorganisasian kelas. (3) dukungan pembelajaran.

Tabel.1 Garis Besar Pengajaran Berbasis Interaksi

\begin{tabular}{|c|c|c|c|}
\hline Domain & Dimensi & Kualitas Rendah & Kualitas tinggi \\
\hline $\begin{array}{l}\text { Dukungan } \\
\text { emosional }\end{array}$ & Respon Positif & Ada jarak guru dan anak & $\begin{array}{l}\text { Ada hubungan positif, melalui } \\
\text { kebersamaan aktivitas }\end{array}$ \\
\hline \multirow[t]{6}{*}{$\begin{array}{l}\text { Pengorganisasian } \\
\text { kelas }\end{array}$} & Respon Negatif & Guru tampak frustasi, marah & $\begin{array}{l}\text { Tidak adak kegiatan agresi, saling } \\
\text { membantu }\end{array}$ \\
\hline & Sensivitas guru & $\begin{array}{l}\text { Tidak ada support guru dalam } \\
\text { memberikan dukungan } \\
\text { tambahan }\end{array}$ & $\begin{array}{l}\text { guru perduli dengan kebutuhan } \\
\text { anak di kelas }\end{array}$ \\
\hline & $\begin{array}{l}\text { Penghargaan } \\
\text { pada anak }\end{array}$ & Teacher center & G \\
\hline & & $\begin{array}{l}\text { Guru sangat kurang mengatur } \\
\text { perilaku yang bermasalah }\end{array}$ & $\begin{array}{l}\text { Perilaku konsisten dan proaktif } \\
\text { dalam dalam mengelola perilaku }\end{array}$ \\
\hline & Produktivitas & $\begin{array}{l}\text { Kegiatan rutin tidak } \\
\text { membangun perilaku atau } \\
\text { ketrampilan yang harus } \\
\text { dikerjakan }\end{array}$ & $\begin{array}{l}\text { Kegiatan rutin anak membangun } \\
\text { pembelajatan yang bermakna }\end{array}$ \\
\hline & $\begin{array}{l}\text { Desain } \\
\text { pembelajaran }\end{array}$ & $\begin{array}{l}\text { Guru tidak membangun } \\
\text { aktivitas yang menimbulkan } \\
\text { minat anak }\end{array}$ & $\begin{array}{l}\text { Guru secara aktifmembangun } \\
\text { minat anak dan berpusat pada } \\
\text { anak }\end{array}$ \\
\hline \multirow{4}{*}{$\begin{array}{l}\text { Dukungan } \\
\text { Pembelajaran }\end{array}$} & Konsep & Pembelajaran berbasis & pembelajarg bermakna \\
\hline & perkembangan & fakta,hafalan & \\
\hline & Umpan balik & jarang melakukan umpan balik & $\begin{array}{l}\text { Guru memberikan kesempatan } \\
\text { anak untuk berpartisipasi }\end{array}$ \\
\hline & $\begin{array}{l}\text { Model } \\
\text { berbahasa }\end{array}$ & $\begin{array}{l}\text { Sedikit percakapan, anak } \\
\text { diharapkan tenang }\end{array}$ & $\begin{array}{l}\text { Guru dan anak membangun } \\
\text { percakapan dan membantu } \\
\text { kempuan berkomunikasi }\end{array}$ \\
\hline
\end{tabular}


Peran sumber daya manusia sangat penting dalam pelakanaan mutu lembaga, yaitu kepala sekolah, Guru, orang tua siswa dan siswa. Guru mempunyai peran yang sangat penting karena bertanggung jawab terhadap proses belajar mengajar dan capaian pembelajaran anak/ Maka kualitas pembelajaran menjadi hal yang sangat penting dalam standar dalam salah satu standar mutu anak(Jeon et al., 2010). Termasuk Bagaimana dapat memberikan pengalaman yang bermakna dalam pengembangan kognitif anak(Vallotton \& Fischer, 2008). Pengalaman individu anak berhubungan dengan mutu kelas dan membentuk kesiapan anak pada pendidikan selanjutnya (Jeon et al, 2010). Demikian juga tentang observasi yang perlu dilakukan guru dikelas dalam peningkatan kualitas kelas dapat meningkatkan mutu pendidikan di lembaga PAUD. (La Paro et al., 2009)

Kepala PAUD dan pendidik menjadi elemen yang penting karena mereka berperan sebagai ujung tombak. Sementara orang tua siswa dan siswa juga tidak dapat diabaikan karena mereka adalah pengguna jasa layanan PAUD. Jadi keduaanya, baik kepala sekolah dan pendidik membutuhkan orang tua dan siswa demikian juga sebaliknya. Prinsip saling membutuhkan inilah yang akan melandasi dalam menetapkan tujuan bersama dan melakukan kerjasama melaluiwadah lembaga PAUD.

Kepala sekolah sebagai pemimpin dalam pelaksanaan pengelolaan lembaga PAUD yang bermutu diharapkan memiliki berbagai ketrampilan yaitu Ketrampilan konseptual, ketrampilan hubungan manusia dan ketrampilan teknis. Ketrampilan konseptual berhubungan dengan gagasan untuk mendapatka pendekatan baru dalam menjalankan lembaga PAUD. Hal ini ada hubungannya dengan kemampuan lembaga meyusun perencanaan, pengorganisasian, menentukan kebijakan dan pemecahan masalah dalam penyelenggraaan PAUD.

Ketrampilan human relationship merupakan kemampuan berhubungan dengan manusia yang harus dimiliki kepala lembaga dalam rangka membangun sistem komunikaso dua arah untuk menciptakan citra sekolah yang positif. Perilaku yang mencerminkan ketrampilan hubungan manusia adalah menunjukkan semanagat kerja, memberikan bimbingan maupun bantuan kepada pendidikan maupun staff. Menyenangkan dan menghormati stake holder dan memiliki integritas tinggi dan tegas dalam mengambil kebijakan, dan menyelesaikan masalah pada PAUD yang dipimpinnya.

Ketrampilan teknis dapat dilihat dari bagaimana kepala PAUD menjalankan supervisi secara berkala kepada pendidiknya, mengevaluasi, mereview, merevisi layanan PAUD, membuat perencanaan progam kegiatan baik di luar maupun di dalam, mengevaluasi program, membantu pendidik melakukan perbaikan pembelajaran, dan mendiagnosa kesulitan belajar anak. melakukan koordinasi agar program berjalan efektif.

\section{SIMPULAN}

Terdapat 8 standar yang digunakan dalam menetapkan standar mutu PAUD di Indonesia merujuk pada Peraturan Menteri nomor 137 tahun 2014. Pelaksanaan mutu lembaga dilakukan melalui mutu internal oleh dinas pendidikan dan mutu eksternal oleh Badan Akreditasi Nasional (BAN). Namun sebagai rekomendasi untuk penelitian selanjutnya, peneliti belum menggali lebih dalam bagaimana untuk indikator bagi lembaga PAUD inklusi atau anak-anak yang berkebutuhan khusus, termasuk perlunya panduan dalam standar pembelajaran sebagai bagian indikator mutu.

\section{UCAPAN TERIMAKASIH}

Penulis mengucapkan terima kasih kepada Universitas Slamet Riyadi Surakarta yang telah memfasilitasi penelitian ini dan tim penelitia hingga selesai, serta pengelola jurnal Obsesi yang telah menerbitkan artikel hasil penelitian ini. 


\section{DAFTAR PUSTAKA}

Bernard van Leer Foundation. (2008). Early childhood education: questions of quality. Early Childhood Matters, (110).

Ereky-stevens, K. (n.d.). a Review of Research on the Effects of Early Childhood Education. 1-100.

Farquhar, S. E. (1990). Quality in early education and care: What do we mean? Early Child Development and Care, 64(1), 71-83. https://doi.org/10.1080/0300443900640108

Flores, R. L., Curby, T. W., Coleman, H., \& Melo, K. (2016). Using Early Learning Standards to Provide High-Quality Education for All Children: The Early Learning Guidelines Toolkit. Theory into Practice, 55(2), 145-152. https:// doi.org/10.1080/00405841.2016.1157422

Gambaro, L., Stewart, K., \& Waldfogel, J. (2015). A question of quality: Do children from disadvantaged backgrounds receive lower quality early childhood education and care? British Educational Research Journal, 41(4), 553-574. https://doi.org/10.1002/berj.3161

Goldberg, J. S., \& Cole, B. R. (2002). Quality Management in Education: Building Excellence and Equity in Student Performance. Quality Management Journal, 9(4), 8-22. https://doi.org/10.1080/10686967.2002.11919033

House, M., Street, M., Wt, L., Landerholm, E., Gehrie, C., \& Hao, Y. (2007). Educating early childhood teachers for the global world Educating early childhood teachers for the global world. (October 2014), 37-41. https:// doi.org/10.1080/0300443042000187095

Ishimine, K., \& Tayler, C. (2014). Assessing quality in early childhood education and care. European Journal of Education, 49(2). https://doi.org/10.1111/ejed.12043

Jeon, H. J., Langill, C. C., Peterson, C. A., Luze, G. J., Carta, J. J., \& Atwater, J. B. (2010). Children's individual experiences in early care and education: Relations with overall classroom quality and children's school readiness. Early Education and Development, 21(6), 912-939. https://doi.org/10.1080/10409280903292500

La Paro, K. M., Hamre, B. K., Locasale-Crouch, J., Pianta, R. C., Bryant, D., Early, D., ... Burchinal, M. (2009). Quality in kindergarten classrooms: Observational evidence for the need to increase children's learning opportunities in early education classrooms. In Early Education and Development (Vol. 20). https://doi.org/10.1080/10409280802541965

Montessori, M., \& Burstyn, J. N. (1982). History of Education Society. History of Education Quarterly, 22(1), 116-116. https://doi.org/10.1017/s0018268000021968

Mujkanovic, E., Mujkanovic, E., Pasalic, A., Biscevic, I., \& Memisevic, H. (2017). Quality of educational support for children with autism spectrum disorder in Bosnia and Herzegovina-perception of parents and professionals. International Electronic Journal of Elementary Education, 9(4), 829-836.

Pendidikan, M., Kebudayaan, D. A. N., \& Indonesia, R. (2014). PERMENDIKBUD No. 137. 13.

Rao, N., Richards, B., Sun, J., Weber, A., \& Sincovich, A. (2019). Early Childhood Research Quarterly Early childhood education and child development in four countries in East Asia and the Pacific §. Early Childhood Research Quarterly, 47, 169-181. https://doi.org/10.1016/j.ecresq.2018.08.011

Schulz, M. (2015). The Documentation of Children's Learning in Early Childhood Education. Children and Society, 29(3), 209-218. https://doi.org/10.1111/chso.12112

Siraj-Blatchford, I. (2009). Conceptualising progression in the pedagogy of play and sustained shared thinking in early childhood education: A Vygotskian perspective. Educational and Child Psychology, 26(2), 77-89.

TUBAKI, M., \& MATSUISHI, T. (1972). On the pedagogical theory of Maria Montessori. Schocken Books Inc., 1-4. Retrieved from http:/ / matsuishi-lab.org/montessorisummaryJ_E.html

Vallotton, C. D., \& Fischer, K. W. (2008). Cognitive Development. In Encyclopedia of Infant and Early Childhood Development (Vol. 1-3, pp. 286-298). https://doi.org/10.1016/B978012370877-9.00038-4. 